\title{
Food Consumption Patterns among Pre-School Children 3 - 5 Years Old in Mateka, Western Kenya
}

\author{
Amos Kipkemoi Ronoh'1, Gertrude Mercy Were', Florence Wakhu-Wamunga1, \\ John Brian Wamunga ${ }^{2}$
}

${ }^{1}$ Deparment of Family and Consumer Sciences, University of Eldoret, Eldoret, Kenya

${ }^{2}$ Kenyatta University, Nairobi, Kenya

Email: ronoamos00@gmail.com

How to cite this paper: Ronoh, A.K., Were, G.M., Wakhu-Wamunga, F. and Wamunga, J.B. (2017) Food Consumption Patterns among Pre-School Children 3 - 5 Years Old in Mateka, Western Kenya. Food and Nutrition Sciences, 8, 801-811.

https://doi.org/10.4236/fns.2017.88057

Received: May 9, 2017

Accepted: August 11, 2017

Published: August 14, 2017

Copyright $\odot 2017$ by authors and Scientific Research Publishing Inc. This work is licensed under the Creative Commons Attribution International License (CC BY 4.0).

http://creativecommons.org/licenses/by/4.0/

\begin{abstract}
Hunger and malnutrition are burdens that are pronounced in developing countries where they manifest themselves in the forms of protein energy malnutrition. Malnutrition compromises the child's immune system leading to direct mortality and increased vulnerability to infectious diseases stunting and poor brain development. This study sought to analyze the food consumption patterns of children 3 - 5 years old attending Mateka Primary school, Bungoma County. This study adopted a cross sectional survey. One hundred and twenty five (125) children selected from three ECD classes in the school formed the sample size. Purposive and simple random sampling techniques were used to select the study area and the children respectively. Structured questionnaires were administered to the caregivers of the children. Information on demographics, socio-economic status, and food consumption patterns were gathered. Food consumption patterns were assessed using a HDDS and a quantitative food frequency questionnaire. Socio-demographic data was analyzed using (SPSS) Version 21 (2007) and dietary data was analyzed using Nutri-Survey for Windows (2007). Results revealed that most of the households were of low socio-economic characteristics. The most consumed foods were cereals, roots and tubers. Majority (55.2\%) of the children had low dietary diversity, $29.1 \%$ had medium dietary diversity and $15.7 \%$ had greater dietary diversity. The children were deficient in energy, protein, Vitamin A, Iron and Zinc. It can be concluded that the diets fed to the children are inadequate to meet their nutrient intakes for physiological development and growth. Further research should be done to document the prevalence of micronutrient malnutrition among the children.
\end{abstract}




\section{Keywords}

Pre-School, Dietary Diversity, Food Consumption Patterns

\section{Introduction}

Malnutrition is the most compelling risk factor to mortality and morbidity affecting millions of children globally [1]. Malnutrition accounts for $54 \%$ of mortality cases in children below 5 years in developing countries [2]. Furthermore, malnutrition compromises the child's immune system leading to direct mortality and increased vulnerability to infectious diseases, stunting and poor brain development which hinders academic achievement school going children [3] [4] and reduced work capacity in adulthood [5].

During the first 100 days of life, it is very important that children are fed on diets that are adequate to meet their physiological needs for growth and development as this is the most critical period of child's growth [6]. This therefore implies that food given to the children should be diverse, within and between food groups. Validation of the dietary diversity scores and food variety score has made the assessment of dietary adequacy among young children easy [7] [8] and has also been used to give an insight into the child feeding practices [9].

Dietary diversity has been correlated with improved nutritional status of children [7]. However in developing countries, diets fed to children usually lack in variety and are monotonous staples and cereals with little intake of animal source foods [10]. This becomes an exacerbating factor to malnutrition because children are at their critical point of growth where they require adequate nutrients to meet the growth demands. Therefore this study sought to assess the food consumption patterns of children pre-school children from Mateka, Bungoma County.

\section{Materials and Methods}

\subsection{Research Design}

A cross sectional survey was used collect data on socio-economic characteristics of the households and dietary diversity and the nutritional adequacy of the children's diets.

\subsection{Subjects and Sampling}

This study comprised all the children in Early Childhood Education (E.C.D) (Baby, Middle and Top) classes aged 3 - 5 years attending Mateka Primary school in Bungoma County. These school children and their caregivers were the target population. One hundred and twenty five parents (125) were be randomly sampled to answer the questionnaire on household socio-demographics and the household diet diversity questionnaire. 


\subsection{Study Setting}

This study was conducted in Mateka primary school, Bungoma County, Western Kenya. Mateka is found in Bumula Location. Bungoma County is found in Western Kenya and has a population of $1,375,063$ people [11]. It covers an area of 20,693 $\mathrm{km}^{2}$. It borders Busia, Kakamega and Trans-Nzoia counties. The climatic factors favor agriculture as temperatures range between a minimum of $15^{\circ} \mathrm{C}$ and a maximum of $27^{\circ} \mathrm{C}$ with an average rainfall of $1500 \mathrm{ml}$. The main economic activity is farming, and the major crops grown in the area include maize, sorghum, cassava, beans and soybeans.

\subsection{Data Collection}

Structured questionnaires were used to obtain data on socio-demographic characteristics of the households of the children who participated in this study-food consumption patterns and diet diversity. The caregivers of the target child responded to the interview questions.

A household dietary diversity questionnaire recommended by FAO [10] was adopted and modified for this study. The recall included foods from 16 food groups which include Cereals; Vitamin A rich vegetables and tubers; White roots and tubers; Dark green leafy vegetables; Other vegetables; Vitamin A rich fruits; Other fruits; Organ meat; Flesh meat; Eggs; Fish; Pulses/Legumes, nuts and seeds; Milk and milk products; Oils and fats; Sweets and sugar and condiments and spices. Dietary diversity scores (DDS) were calculated based on the number of food groups consumed in the last 24 hours according to [10].

Questions were directed to the parent, but the target child was also present during the interview to assist in indicating foods eaten outside home. Subjects were asked to state what they had eaten the last 24 hours before the interview. The researcher obtained a range of household utensils: glasses, spoons, cups and plates were used to estimate the amounts of food and beverages. Utensils were used as visual aids to ensure accuracy in the estimation of the portion sizes. Ingredients used in the food preparation and the method of preparation were sought. Seasonal fruits and vegetables were purchased and used in the estimation of portion sizes.

\subsection{Data Management and Analysis}

Data on socio-demographics of the caregivers was entered and analyzed using SPSS Version 21 (2007). Data from quantitative food frequency questionnaire was entered into Nutri-survey for Windows (2007) for quantitative calculations and amounts was converted to gram equivalents.

\subsection{Ethical Review and Informed Consent}

Permission to do this research was sought from the National Commission for Science Technology and Innovation (NACOSTI). Written consent was sought from the parents or the guardians of the children. Children gave a verbal consent. 
Permission was obtained from the school administration before carrying out the survey in the school. Confidentiality was ensured through use of codes instead of the names of the parents or the children.

\section{Results}

\subsection{Socio-Demographic Characteristics of the Respondents}

Most (38\%) of the respondents were be between 25 - 35 years old. The least age of the respondents was those above 50 years (3\%). More than half (56\%) of the caregivers had primary level of education, whereas those who had achieved university or college education were only $9 \%$ (Table 1 ). Most (55\%) of the respondents have $1-5$ acreages of land under food production. The average number of children living in the households was 4.3 children. More than half (56\%) of the respondents earn between Kenya shillings 1001 - 5000. Twelve (12) percent of the respondents earned less than Kenya shillings 1000 per month. The mean household monthly income was Ksh 2700 . Of the children, most (53\%) of them were 4 - 5 years old whereas the rest $(47 \%)$ were 3 years old. Fifty five (55\%) of the children were boys and the girls were $45 \%$ of the children.

\subsection{Food Consumption per Food Groups}

The most commonly consumed food groups in the area were cereal (maize, sorghum, rice and wheat), tubers (cassava and sweet potatoes). The other commonly consumed foods included dark green vegetables and legumes. The least consumed foods were foods from animal sources such as organ meat, fish, eggs, milk and flesh meat. Vitamin A rich foods and vegetables were rarely consumed too (Table 2).

\subsection{Dietary Diversity Scores}

According [10] Household Diet Diversity Score (HDDS) categorization, consumption of less than 3 food groups is classified as poor dietary diversity, 4 - 5 food groups is classified as medium dietary diversity and greater or equal are classified as high dietary diversity. The results from this study showed that majority (55.2\%) of the children had low dietary diversity, $29.1 \%$ had medium dietary diversity and $15.7 \%$ had greater dietary diversity. This study revealed that most of the children's diet was not diverse.

\subsection{Nutritional Adequacy of the Children's Diet}

For children to achieve maximal growth and development, most of their nutrient intake should be met [12]. Protein Energy Malnutrition, Vitamin A, Zinc and Iron deficiencies are most prevalent deficiencies affecting children globally. Therefore it was necessary to establish the intake of these nutrients among these children to find out if they are deficient. The results have been presented in Table 3 for children aged 3 years and Table 4 for children aged 4 - 5 years. The values for individual intake by the children were also compared against the 
Table 1. Socio-demographic characteristics of the respondents.

\begin{tabular}{|c|c|c|}
\hline Variable & & $\begin{array}{l}\text { Percentage (\%)of the } \\
\text { respondents }\end{array}$ \\
\hline \multirow{4}{*}{ Care giver } & Mother & 89 \\
\hline & Father & 3 \\
\hline & Grandparent & 3 \\
\hline & Aunt/uncle & 5 \\
\hline \multirow{5}{*}{ Caregiver's age } & $15-24$ & 18 \\
\hline & $25-35$ & 38 \\
\hline & $36-44$ & 10 \\
\hline & $45-49$ & 26 \\
\hline & 50 and above & 3 \\
\hline \multirow{4}{*}{ Marital status } & Single & 2 \\
\hline & Married & 89 \\
\hline & Widowed & 6 \\
\hline & Divorced & 3 \\
\hline \multirow{4}{*}{ Level of education } & None & 10 \\
\hline & Primary & 56 \\
\hline & Secondary & 25 \\
\hline & College/university & 9 \\
\hline \multirow{5}{*}{ Size of the household } & 1 - 2 Children & 13 \\
\hline & 3 children & 12 \\
\hline & 4 children & 45 \\
\hline & 5 children & 23 \\
\hline & More than 5 children & 7 \\
\hline \multirow{5}{*}{ Current occupation } & Employed unskilled & 37 \\
\hline & Employed skilled & 10 \\
\hline & Housewife & 45 \\
\hline & Farmer & 5 \\
\hline & Self-employed & 3 \\
\hline \multirow{3}{*}{ Size of land allocated to crops } & 1 acre and below & 45 \\
\hline & $1-5$ acres & 55 \\
\hline & 5 acres and above & 10 \\
\hline \multirow{4}{*}{ Income levels of the caregivers } & Less than 1000 & 12 \\
\hline & $1001-5000$ & 56 \\
\hline & $50,001-10,000$ & 12 \\
\hline & 10,000 and above & 10 \\
\hline
\end{tabular}

different age groups' RDA values in order to determine if the daily intake of the nutrients met the recommended dietary intake for the specific age group. The findings show that most children in both age groups did not meet their RDAs for all the selected nutrients. 
Table 2. Dietary intake per food group.

\begin{tabular}{ccc}
\hline Food groups & N & Percentage \\
\hline Cereals & 125 & 100 \\
Vitamin A rich vegetables & 55 & 43.5 \\
Dark green vegetables & 111 & 89 \\
Other vegetables & 122 & 97 \\
Vitamin A rich fruits & 40 & 32 \\
Roots and tubers & 120 & 96 \\
Organ meat (Iron rich meat) & 16 & 12.5 \\
Flesh meat (Beef, chicken) & 11 & 8.4 \\
Eggs & 19 & 14.9 \\
Fish & 36 & 28.7 \\
Legumes & 71 & 67.8 \\
Milk & 26 & 25 \\
Oil and fats & 84 & 73 \\
\hline
\end{tabular}

Table 3. Nutrient intake of 3 year old children.

\begin{tabular}{ccccc}
\hline Nutrient & Mean \pm sd & $\begin{array}{c}\text { Nutrient intake } \\
\text { range (min to max) }\end{array}$ & RDA $^{\mathrm{a}} / \mathbf{E E R}^{\mathrm{b}}$ & $\begin{array}{c}\text { Deficient } \\
\text { (surplus) }\end{array}$ \\
\hline Proteins (g) & $8 \pm 2.5$ & $4.2-11.8$ & 13 & 5 \\
Iron (mg) & $5.6 \pm 1.1$ & $3.4-6.5$ & 7 & 1.4 \\
Energy (Kcal) & $854 \pm 67$ & $566-1002$ & $992-1046$ & $138-192$ \\
Vitamin A ( $\mu$ g) & $231 \pm 34$ & $196-267$ & 300 & 69 \\
Zinc (mg) & $1.7 \pm 0.67$ & $0.8-2.8$ & 3 & 1.3 \\
\hline
\end{tabular}

aBased on nutrient requirements for children 2 - 3 years old as recommended by [13]; ${ }^{\text {}}$ The Estimated Energy Requirement (EER) represents the average dietary energy intake that will maintain energy balance in a healthy person of a given gender, age, weight, height, and physical activity level.

Table 4. Nutrient intake of 4 - 5 year old children.

\begin{tabular}{|c|c|c|c|c|}
\hline Nutrient & Mean $\pm s d$ & $\begin{array}{l}\text { Range of nutrient } \\
\text { intake (min to } \max \text { ) }\end{array}$ & $\mathrm{RDA}^{\mathrm{a}} / \mathrm{EER}^{\mathrm{b}}$ & $\begin{array}{l}\text { Deficient } \\
\text { (surplus) }\end{array}$ \\
\hline Proteins (g) & $13 \pm 4.5$ & $10.5-16.8$ & 19 & 6 \\
\hline Iron (mg) & $6.6 \pm 1.1$ & $4.4-8.9$ & 10 & 3.4 \\
\hline Energy (Kcal) & $1386 \pm 87$ & $1243-1567$ & $1642-1742$ & $256-356$ \\
\hline Vitamin A $(\mu g)$ & $296 \pm 34$ & $245-384$ & 400 & 104 \\
\hline Zinc (mg) & $2.5 \pm 1.8$ & $2.3-3.9$ & 5 & 2.5 \\
\hline
\end{tabular}

${ }^{a}$ Based on nutrient requirements for children 4 - 5 years old as recommended by [13]; ${ }^{\text {The Estimated }}$ Energy Requirement (EER) represents the average dietary energy intake that will maintain energy balance in a healthy person of a given gender, age, weight, height, and physical activity level. 


\section{Discussion}

\subsection{Socio-Demographic Characteristics}

More than half (56\%) of the caregivers had primary level of education, whereas those who had achieved university or college education were only $9 \%$. This could be due to the cultural practice where children in the area are married early, where most of the women are married at the age of $12-16$ years [14]. Most of the families had a small acreage of land under food production. This is a pointer of food insecurity as they cannot sustainably produce enough food for their households for the whole year. Heightened food insecurity in Kenya has been contributed by low agricultural production because of land fragmentation [15]. Most of the families earned less than one dollar a day. This could be attributed to the low education of the level of the respondents. This means that they cannot be able to secure permanent or well paying jobs, where most of them were unskilled labourers and housewives. Similar results to this have been reported in Western Kenya [16].

\subsection{Food Consumption per Food Groups}

This study showed that cereals and starchy roots and tubers were the most consumed foods and that they contributed majorly to the energy intake of the children. The most commonly consumed staples were maize, sorghum and cassava. The reason is that most of these staples are commonly grown in the area due to favorable climate [17]. The second reason for high consumption is that starchy staples are less expensive in comparison to foods from other food groups. A trend analysis by [18] found that in the Sub-Saharan Africa, there is a shift from diets that are diverse to those that are predominantly high in carbohydrates because of declining incomes. This is further justified by the fact that starchy staple foods are cheaper as compared to animal source foods, fruits and vegetables.

Individually, consumption of fruits among the children was very low. Fruits are an invaluable source of energy, iron and vitamins A and C. According to [19], the demand for fruits increases with increase in the household income, although the proportion of the total expenditure allocated to it tends to decline. The implication is that the demand for fruits and vegetables at lower incomes is much lower probably because low income households must prioritize the fulfillment of their basic energy requirements to avoid hunger. Fruits have been documented to be expensive sources of energy [20].

Majority of the children consumed vegetables and this could be due to the reason that most households in Western Kenya grow these types of vegetables. Most food consumption surveys in Western Kenya have reported almost 100\% consumption of vegetables regardless of the recall period. Studies [16] [21] have shown that most of the pre-school children from Western Kenya consume a considerable amount of vegetables. A study in South Africa indicated a negative significant influence on consumption of vegetables with education, where per 
unit increase in household education, there was a 4.116 times decrease in leafy vegetables consumption [22]. This could also be true in this study because most of the households were from a low socio-demographic status. Furthermore, vegetables have been seen as a cheap source of food for low income households as they can be easily procured and prepared [16].

Vitamin A rich vegetables and fruits intake was low. This becomes an exacerbating factor to increased prevalence of Vitamin AD eficiency [VAD] considering that Western Kenya has the lowest Vitamin A Supplementation [VAS] coverage at $19.8 \%$ compared to $30.3 \%$ nationally [11]. [23] in three counties (Busia, Vihiga and Bungoma) in Western Kenya showed that despite the high prevalence of VAD in the area, most of pre-natal and post-natal mothers were not aware about VAD, VAS and the importance of consumption of vitamin A rich foods in their household diets.

\subsection{Dietary Diversity Scores}

Results showed that most of the children's diet was not diverse. This could be attributed to low socio-economic status of the respondents, and that most of them had small pieces of land allocated to food production. This can be attributed to food insecurity, in terms of accessibility and stability of food, which are key elements of food security. Poor dietary diversity is a critical problem in developing countries [10]. Studies have shown that dietary diversity is an indicator of the quality of diet, particularly the intake of micronutrients among young children [8] [10]. A high dietary diversity has also been positively correlated with improvement in the nutritional status of children [10]. This shows that the preschool children in this region do not consume diverse diets.

\subsection{Nutritional Adequacy of the Children's Diet}

Energy: The mean energy intake for children aged 3 years was $854 \mathrm{Kcal}$ (Table 3) whereas for the 4 - 5 years children were $1386 \mathrm{Kcal}$ (Table 4). The mean energy intake for the children in both age groups did not meet the EER. This shows that there was a section of the population that did not fulfill their energy requirements and therefore there was a risk for energy deficiency. This could be attributed to the insufficient intake of carbohydrates, fats and proteins which are the main sources of energy. Wasted children need energy dense foods for catch up growth [24]. Furthermore, deficiency of energy increases the chances of the children developing protein energy malnutrition. These findings corroborate with those of [25] reported that pre-school children from Western Kenya did not meet their energy requirements.

Proteins: On average, the children did not meet their protein intake. The main sources of protein in the diet were cereals and legumes. Animal source foods of proteins were rarely consumed. This could be attributed to the high cost of animal source foods. [26] documented that when animal products are priced out of reach of many low income households, they are likely to rely more on 
staple grains and legumes as their protein sources. A review by [27] showed that most of the Kenyan children did not meet their protein needs. This therefore is a pointer that these children are likely to suffer from protein deficiency leading to marasmus.

Vitamin A: This shows that both ages did not meet their Vitamin A requirements by a deficit of $69 \mu \mathrm{g}$ and $104 \mu \mathrm{g}$ respectively. This is a pointer that a section of the children were at risk of Vitamin A Deficiency. This could have been due to low consumption of vitamin A rich fruits and vegetables. Similar results have been documented by [28] in Western Kenya where children (6 - 59 months) from this region were found to be vitamin A deficient, a conclusion that was drawn from low intake of Vitamin A rich foods in this age group. Others factors that could influence the adequacy of vitamin A intake include seasonality of fruits, food preparation methods and availability of money to buy fruits. The implication is that these children are likely to suffer from Vitamin A deficiency, which pre-disposes them to night blindness.

Zinc: This shows that the children met the nutrient requirement by half. The low zinc intake indicates that there is a high risk of the children suffering from zinc deficiency. This is because consumption of animal source foods which are rich sources of zinc was low. Even though legumes were the major source of zinc, bioavailability of zinc is low [29]. Inadequate zinc intake in the diet has been implicated for high levels of stunting in children [30]. A study by [31] among preschool children from Western and Eastern Kenya showed that the complementary foods fed to the children were low in zinc and therefore did not meet the WHO recommendations for growth and development of young children. In general, the findings of this study on food consumption patterns and nutrient adequacy agree with those of populations found in developing countries where diets are monotonous and lack in variety.

\section{Conclusion}

Most of the households in the study area are of low socio-economic and demographic status. Most attained primary level of education and earn less than 1 dollar a day. There is nutrient inadequacy in the diet of the children. This is attested by inadequacy in key macronutrients (protein) and micronutrients ( $\mathrm{Vi}$ tamin A, Iron and Zinc), and low diet diversity of children.

\section{Recommendation}

There is need for more research to document the extent of micronutrient malnutrition among the children in the study area to form basis for further nutrition intervention.

\section{Acknowledgements}

This research was made possible through funding from MU-K_VLIR-UOS AGBIO PROJECT. 


\section{References}

[1] World Hunger Education Services (2016) 2016 World Hunger and Poverty Facts and Statistics. http://www.worldhunger.org/

[2] United Nations International Children's Emergency Fund (2013) The Right Ingredients: The Need to Invest in Child Nutrition, United Kingdom. United Nations International Children's Emergency Fund, New York.

[3] Brown, J.L. and Pollit, E. (1996) Malnutrition Poverty and Intellectual Development. Scientific American, 274, 38-43.

https://doi.org/10.1038/scientificamerican0296-38

[4] Khanam, R.H.S., Nghiem, T. and Rahman, M.M. (2011) The Impact of Childhood Malnutrition on Schooling: Evidence from Bangladesh. Journal of Biosocial Sciences, 43, 437-451. https://doi.org/10.1017/S0021932011000149

[5] Carba, D.B., Tan, V.L. and Adir, L.S. (2009) Early Childhood Length-Age Is Associated with Work Status of Filipino Young Adults. Economics and Human Biology, 7, 7-17. https://doi.org/10.1016/j.ehb.2009.01.010

[6] Dewey, K. (2003) Guiding Principal for Complementary Feeding of the Breastfed Child: Pan American Health Organization/World Health Organization. Pan American Health Organization, Geneva, 1-43.

[7] Nti, C.A. (2011) Dietary Diversity Is Associated with Nutrient Intakes and Nutritional Status of Children in Ghana. Asian Journal of Medical Sciences, 2,105-109. https://doi.org/10.3126/ajms.v2i2.4179

[8] Steyn, N.P., Nel, J.H., Nantel, G., Kennedy, G. and Labadarios, D. (2005) Food Variety and Dietary Diversity Scores in Children: Are They Good Indicators of Dietary Adequacy? Public Health Nutrition, 9, 644-650.

[9] World Health Organization (2009) Indicators for Assessing Infant and Young Child Feeding Practices. Part II: Measurement. World Health Organization, Geneva.

[10] Kennedy, G.L., Pedro, M.R., Seghieri, C., Nantel, G. and Brouwer, I. (2007) Dietary Diversity Score Is a Useful Indicator of Micronutrient Intake in Non-Breast-Feeding Filipino Children. Journal of Nutrition, 137, 472-477.

[11] Kenya National Bureau of Statistics (KNBS) and ICF Macro (2015) Kenya Demographic and Health Survey 2014-2015. Kenya National Bureau of Statistics and ICF Macro, Calverton.

[12] United Nations International Children's Emergency Fund/World Health Organization/World Bank (2015) Levels and Trends in Child Malnutrition. UNICEF-WHOWorld Bank Group Joint Child Malnutrition Estimates. Key Findings of the 2015 Edition. https://www.unicef.org/media/files/JME 2015 edition Sept 2015.pdf

[13] Institute of Medicine (IOM) (2000) Dietary Reference Intakes: Application in Dietary Assessment. National Academy Press, Washington DC, 73-105.

[14] Kenya National Bureau of Statistics and Society for Information Display (2013) Exploring Kenya's Inequality. Pulling Apart or Pooling Together. Focus on Bungoma County. Kenya National Bureau of Statistics and Society for Information Display, Nairobi.

[15] Ichera, K.B. (2015) Household Food Insecurity and Coping Strategies among Small Scale Farmers in Tharaka Central Division of Tharaka South District, Kenya. International Journal of Humanities Social Sciences and Education, 2, 63-76.

[16] Walingo, M.K. and Ekesa, B.N. (2013) Nutrient Intake, Morbidity and Nutritional Status of Pre-School Children Are Influenced by Agricultural and Diet Diversity in 
Western Kenya. Pakistan Journal of Nutrition, 12, 854-859. https://doi.org/10.3923/pjn.2013.854.859

[17] Macharia, I., Orrr, A. and Schipmann, C. (2012) Cereal Consumption Pattern in Kenya. International Crops Research Institute for the Arid and Semi-Arid Tropics (ICRISAT), Nairobi, 1-35.

[18] Thompson, B. and Amoroso, L. (2009) Combating Micronutrient Deficiencies: Food-Based Approaches. Food and Agriculture Organization, Rome.

[19] Ruel, M.T., Minot, N. and Smith, L. (2004) Patterns and Determinants of Fruit and Vegetables Consumption in Sub-Saharan Africa. Background Paper for the Joint FAO/WHO Workshop. The Joint FAO/WHO Workshop, Kobe.

[20] Prescott, N. and Pradham, M. (1997) A Poverty Profile of Cambodia. Discussion Paper No. 373. World Bank, Washington DC.

[21] Waswa, M., Keding, B.G., Irmgard, J., Johannes, H. and Michael, B.K. (2015) Nutritional Status, Dietary Diversity and Morbidity among Infants and Children Aged 6-23 Months in Rural Western Kenya. http://www.bioversity.org

[22] Taruvinga, A. and Nengovhela, R. (2015) Consumers' Perceptions and Consumption Dynamics of African Leafy Vegetables (ALV's): Evidence from Feni Communal Area, Eastern Cape Province, South Africa. Proceedings of 5 th International Conference on Biomedical Engineering and Technology, Seoul, 10-11 March 2015, 85-95.

[23] Oyunga, A.M., Omondi, O.D. and Grant, E.K.F. (2016) Awareness in the Context of Prevalence of Vitamin a Deficiency among Households in Western Kenya Using a Cross-Sectional Survey. Journal of Food and Nutrition, 3, 55-64.

[24] Michaelsen, K.F., Floppe, C., Root, N., Kaestel, P., Stougard, M., Laurtzen, L., Molgard, C., Girma, T. and Friis, H. (2009) Choice of Food Ingredient for Moderately Malnourished Children 6 Month to 5 Years of Age. University of Copenhagen, Denmark. Journal of Food and Nutrition, 30, 1-62.

[25] Ekesa, B.N., Walingo, M.K. and Abukutsa-Onyango, M.O. (2009) Accessibility to and Consumption of Indigenous Vegetables and Fruits of Rural Households in Matungu Division, Western Kenya. African Journal of Food, Agriculture, Nutrition and Development, 9, 1725-1738. https://doi.org/10.4314/ajfand.v9i8.48410

[26] Neumann, C.G. and Harris, D.M. (1999) Contribution of Animal Source Foods in Improving Diet Quality for Children in the Developing World. The World Bank, Washington DC.

[27] Bwibo, N.O. and Neumann, C.G. (2003) The Need for Animal Source Foods by Kenyan Children. Journal of Nutrition, 133, 3936S-3940S.

[28] Grant, F., Cole, D., Kirimi, S., Levin, C., Garret, D., Kariuki, S., Ouedarugo, H., Loechi, C., et al. (2016) Prevalence of Vitamin A Deficiency among Infants Participating in the Mama Sasha Proof of Concept Project in Western Kenya.

[29] Akomo, P.O., Egli, I., Okoth, M.W., Bahwere, P., Cercamondi, C.I., Zeder, C., Njage, P.M.K. and Owino, V.O. (2016) Estimated Iron and Zinc Bioavailability in Soybean-Maize-Sorghum Ready to Use Foods: Effect of Soy Protein Concentrate and Added Phytase. Journal of Food Processing \& Technology, 7, 556.

[30] Hambidge, K.M., Miller, L.V., Westcott, J.E. and Krebs, N.F. (2008) Dietary Reference Intakes for Zinc May Require Adjustment for Phytate Intake Based upon Model Predictions. Journal of Nutrition, 138, 2363-2366.

https://doi.org/10.3945/jn.108.093823

[31] Ferguson, E., Chege, P., Kimiywe, J., Wiesmann, D. and Hotz, C. (2015) Zinc, Iron and Calcium Are Major Limiting Nutrients in the Complementary Diets of Rural Children. Maternal and Child Nutrition, 3, 6-20. https://doi.org/10.1111/mcn.12243 
Submit or recommend next manuscript to SCIRP and we will provide best service for you:

Accepting pre-submission inquiries through Email, Facebook, LinkedIn, Twitter, etc. A wide selection of journals (inclusive of 9 subjects, more than 200 journals)

Providing 24-hour high-quality service

User-friendly online submission system

Fair and swift peer-review system

Efficient typesetting and proofreading procedure

Display of the result of downloads and visits, as well as the number of cited articles Maximum dissemination of your research work

Submit your manuscript at: http://papersubmission.scirp.org/

Or contact fns@scirp.org 